\title{
Associations of Plasma Fatty Acid Patterns during Pregnancy with Respiratory and Allergy Outcomes at School Age
}

\author{
Sara M. Mensink-Bout ${ }^{1,2}$, Trudy Voortman ${ }^{3}{ }^{1}$, Marsela Dervishaj ${ }^{1,2}$, Irwin K. M. Reiss ${ }^{4}$, \\ Johan C. De Jongste ${ }^{2}$, Vincent W. V. Jaddoe ${ }^{1,5}$ and Liesbeth Duijts ${ }^{2,4, * \mathbb{D}}$ \\ 1 The Generation R Study Group, Erasmus MC, University Medical Center, \\ 3000 CA Rotterdam, The Netherlands; s.mensink-bout@erasmusmc.nl (S.M.M.-B.); \\ marseladervishaj@gmail.com (M.D.); v.jaddoe@erasmusmc.nl (V.W.V.J.) \\ 2 Department of Pediatrics, Division of Respiratory Medicine and Allergology, Erasmus MC, \\ University Medical Center, 3000 CA Rotterdam, The Netherlands; j.c.dejongste@erasmusmc.nl \\ 3 Department of Epidemiology, Erasmus MC, University Medical Center, \\ 3000 CA Rotterdam, The Netherlands; trudy.voortman@erasmusmc.nl \\ 4 Department of Pediatrics, Division of Neonatology, Erasmus MC, University Medical Center, \\ 3000 CA Rotterdam, The Netherlands; i.reiss@erasmusmc.nl \\ 5 Department of Pediatrics, Erasmus MC, University Medical Center, 3000 CA Rotterdam, The Netherlands \\ * Correspondence: 1.duijts@erasmusmc.nl
}

Received: 8 September 2020; Accepted: 2 October 2020; Published: 7 October 2020

check for updates

\begin{abstract}
Fatty acids might play a role in asthma and allergy development as they can modulate immune responses. We examined among 4260 mother-child pairs participating in a population-based cohort the associations of maternal plasma fatty acid patterns during pregnancy with a child's respiratory and allergy outcomes at school-age. In mid-pregnancy, 22 individual fatty acids were measured from maternal blood. Three patterns were previously identified by principal component analysis: A 'high n-6 polyunsaturated fatty acid (PUFA)', a 'monounsaturated and saturated fatty acid', and a 'high n-3 PUFA' pattern. At the age of 10 years, a child's lung function was assessed by spirometry, current asthma and physician-diagnosed inhalant allergy by questionnaire, and inhalant allergic sensitization by skin prick tests. A higher 'high n-6 PUFA' pattern was associated with a higher forced expiratory volume in $1 \mathrm{~s} /$ forced vital capacity and forced expiratory flow after exhaling $75 \%$ of forced vital capacity (Z-score difference $(95 \% \mathrm{CI}) 0.04(0,0.07)$ and $0.04(0.01,0.07)$, respectively, per SD increase in the fatty acid pattern). We observed no associations of maternal fatty acid patterns with a child's asthma or allergy outcomes. Our results showed limited associations of maternal patterns of high n-6 PUFA concentrations in pregnancy with a better lung function in school-aged children.
\end{abstract}

Keywords: fatty acids; child; inhalant allergic sensitization and allergy; pulmonary function; prospective cohort study

\section{Introduction}

Maternal diet during pregnancy has been related to respiratory and allergy outcomes in childhood [1]. Among many dietary factors, fatty acids may play an important role as they can modulate immune responses and might thereby influence the development of asthma and related diseases. It has been hypothesized that omega-6 (n-6) PUFAs (polyunsaturated fatty acids) stimulate the production of pro-inflammatory metabolites, including prostaglandins, thromboxanes, and leukotrienes, leading to allergic inflammation, whereas omega-3 (n-3) PUFAs can inhibit inflammation [2,3]. However, more recent studies suggest that the inflammatory effects of $n-6$ and n-3 PUFAs might differ between 
individual fatty acids and not be the same in all tissues [4]. Less emphasis has been put on saturated fatty acids (SFA) and monounsaturated fatty acids (MUFA), which might also have immunomodulating properties [5]. Previous intervention and observational studies have mainly focused on maternal PUFAs in relation to a child's respiratory and allergy outcomes and provided inconsistent results [6-10]. A randomized controlled trial has shown that maternal supplementation with n-3 PUFAs during the third trimester of pregnancy reduces the risk of persistent wheeze or asthma in the children in the first 5 years of life with 7 percentage points as compared to children of mothers in the control group but has no effect on allergic sensitization [6]. We previously observed that higher total maternal n-6 PUFA concentrations during pregnancy were associated with a lower risk of asthma but not with airway inflammation [7]. Other observational studies have not found an association of maternal PUFA concentrations during pregnancy with asthma, lung function, or allergic sensitization in children [8-10]. However, these studies have been mainly performed among children in early childhood, while symptoms may arise at later ages. Furthermore, fatty acids interrelate with each other, and these synergistic or additive effects may be missed by previous studies that have examined fatty acids individually or in groups [11]. We aimed to overcome this by using fatty acid patterns, as this approach takes interrelations into account [12].

Therefore, our aim was to examine among 4260 children and their mothers participating in a population-based cohort study the associations of maternal plasma fatty acids patterns during pregnancy with a child's lung function, asthma, inhalant allergic sensitization, and physician-diagnosed inhalant allergy at school-age.

\section{Materials and Methods}

\subsection{Design and Cohort}

This study was embedded in the Generation R Study, a population-based prospective cohort study from early fetal life onwards in Rotterdam, The Netherlands [13]. The study was approved by the Medical Ethical Committee of the Erasmus MC, University Medical Center in Rotterdam, The Netherlands (MEC-2012-165-NL40020.078.12). Written informed consent was obtained from the parents or legal representatives of all participating children. A total of 8663 women were enrolled before 25 weeks of gestation. Complete information on fatty acid profiles was available for 6997 women. Of this group, 6923 women gave birth to singleton live-born children, of whom 4260 had data on lung function, asthma, inhalant allergic sensitization, or physician-diagnosed inhalant allergy at the age of 10 years (Supplementary Figure S1).

\subsection{Maternal Plasma Fatty Acid Patterns}

Maternal venous blood samples for fatty acid composition analysis in plasma glycerophospholipids were drawn in the second trimester of pregnancy [14]. The samples were centrifuged in the regional laboratory, stored at $-80^{\circ} \mathrm{C}$, and transported to the Division of Metabolic Diseases and Nutritional Medicine, Dr. von Hauner Children's Hospital, Ludwig-Maximilians-University of Munich, Germany. As previously described, they were analyzed using gas chromatography, and the average coefficient of variation was $15.7 \%$ [15]. Information on the concentrations was available for 22 individual fatty acids. We previously applied principal component analysis on the weight percentage of the total fatty acids $(w t \%)$ of these 22 fatty acids [12]. Three patterns were identified and were named based on high factor loadings $(\geq 0.20)$ for the respective fatty acids, describing how strongly each individual fatty acid contributes to each fatty acid pattern. The 'high n-6 PUFA' pattern was characterized by high factor loadings for myristic acid (lipid number, factor loading) (14:0, 0.23), palmitoleic acid (16:1n-7, $0.43)$, eicosenoic acid (20:1n-9, -0.25), eicosapentaenoic acid (20:5n-3, -0.33), docosahexaenoic acid (22:6n-3, -0.39), linoleic acid (18:2n-6, -0.45), $\gamma$-linolenic acid (18:3n-6, 0.53), dihomo- $\gamma$-linolenic acid (20:3n-6, 0.44), arachidonic acid (20:4n-6, 0.40), adrenic acid (22:4n-6, 0.85), osbond acid (22:5n-6, 0.82), and mead acid (20:3n-9, 0.53), the 'MUFA and SFA' by myristic acid (14:0, 0.30), palmitic acid (16:0, 0.88), 
margaric acid (17:0, -0.31), stearic acid (18:0, -0.84), palmitoleic acid (16:1n-7, 0.63), oleic acid (18:1n-9, $0.29)$, vaccenic acid $(18: 1 n-7,0.28)$, eicosenoic acid (20:1n-9, -0.31$)$, linoleic acid (18:2n-6, -0.45$)$, and dihomo- $\gamma$-linolenic acid (20:3n-6, 0.42), and the 'high n-3 PUFA pattern' by oleic acid (18:1n-9, $0.21)$, eicosapentaenoic acid (20:5n-3, 0.69), docosapentaenoic acid (22:5n-3, 0.59), docosahexaenoic acid $(22: 6 n-3,0.67)$, linoleic acid $(18: 2 n-6,-0.67)$, eicosadienoic acid (20:2n-6, -0.69$)$, arachidonic acid (20:4n-6, 0.30), and mead acid (20:3n-9, 0.37) (Supplementary Figure S2) [12].

\subsection{School-Age Lung Function and Asthma and Allergy Outcomes}

Children visited our research center at the age of 10 years. Lung function was assessed by spirometry (MS-Pneumo, Vyaire, Würzburg, Germany), according to the American Thoracic Society and European Respiratory Society (ATS/ERS) guidelines, and checked for acceptability and reproducibility [16]. Children who did not meet the reproducibility criteria of at least three curves with a $\leq 5 \%$ deviation in forced expiratory volume in $1 \mathrm{~s}\left(\mathrm{FEV}_{1}\right)$ and forced vital capacity (FVC), but with at least one technical acceptable curve with adequate reach and duration of the plateau $(n=281)$, were included for the current analyses, as including or excluding these children did not influence our results (data not shown). Lung function measures included $\mathrm{FEV}_{1}, \mathrm{FVC}, \mathrm{FEV}_{1} / \mathrm{FVC}$, and forced expiratory flow after exhaling $75 \%$ of $\mathrm{FVC}\left(\mathrm{FEF}_{75}\right)$ and were converted into sex-, height-, age-, and ethnicity-adjusted z-scores according to the Global Lung Initiative reference data [17]. Information on ever asthma, wheezing in the previous 12 months (no, yes less than 4 episodes, yes 4 or more episodes), and on physician-diagnosed inhalant allergy (no, yes) to pollen (hay fever), house dust mite, cat, or dog was obtained from questionnaires based on the International Study on Asthma and Allergy in Childhood (ISAAC) questionnaire [18]. Information on asthma medication use in the past 12 months was obtained during the research center visit. Current asthma (no, yes) was defined as reported ever physician-diagnosed asthma with either wheezing or the use of inhalant medication in the previous 12 months. Inhalant allergic sensitization (no, yes) to house dust mite, five-grass mixture, birch, cat, or dog (ALK-Abelló B.V., Almere, The Netherlands) was measured by skin prick tests using the scanned area method [19]. Skin responses were considered positive if the area of the wheel was $\geq 40 \%$ of that of the histamine response (i.e., histamine equivalent prick index area $\geq 0.40$ ) [19].

\subsection{Covariates}

Questionnaires at enrollment and during pregnancy provided information on maternal age, pre-pregnancy body mass index, educational level, ethnic background, parity, history of asthma or atopy, smoking during pregnancy, folic acid supplementation, and total daily energy intake (kcal) in early pregnancy. Child's sex, gestational age at birth (weeks), and birth weight (grams) were obtained from the midwife and hospital registries or questionnaires at birth. Postal questionnaires at age 6 and 12 months provided information about ever breastfeeding. At the age of 10 years, a child's height and weight were measured, and age-adjusted childhood body mass index standard deviation scores were calculated [20].

\subsection{Statistical Analysis}

Characteristics of included and non-included children, children who did not have information on respiratory or allergy outcomes at the age of 10 years, were compared by using student's $t$-test, Mann-Whitney $U$ test, and chi-square test. Linear and logistic regression models were used to examine the associations of maternal fatty acid patterns with respiratory and allergy outcomes at the age of 10 years. In model 1 (basic model), we adjusted for gestational age at fatty acid measurement and child's sex. In model 2 (confounder model), we additionally adjusted for maternal age, pre-pregnancy body mass index, educational level, ethnic background, parity, smoking during pregnancy, folic acid supplementation, total daily energy intake, and child's breastfeeding. Confounders were included in our model based on the literature [21], if they were associated with both the exposure and the outcome, 
or if they changed the effect estimates with $\geq 10 \%$ compared to the basic model. We considered the confounder model as the main model.

When we observed a statistically significant association of maternal fatty acid patterns with child's respiratory or allergy outcomes, we considered child's growth factors as potential mediators and, therefore, additionally adjusted in model 3 for gestational age at birth and birth weight (early growth model) and in model 4 for child's body mass index at the age of 10 years (childhood growth model). Potential non-linearity of the associations was evaluated by studying maternal fatty acid patterns in quartiles with the lowest quartile as the reference category. We additionally studied the associations of maternal fatty acid patterns with asthma severity as measured by the number of wheezing episodes by using multinomial regression models. Therefore, we created the groups 'no current asthma', 'current asthma without wheezing episodes', 'current asthma with $<4$ wheezing episodes', and 'current asthma with $\geq 4$ wheezing episodes'. Potential effect modifiers that we considered were maternal ethnic background, history of asthma or atopy, as women with atopy might have a different fatty acid metabolism, or child's sex [21]. Additionally, we considered a child's current asthma, inhalant allergic sensitization, and physician-diagnosed inhalant allergy as potential effect modifiers for the associations of maternal fatty acid patterns with a child's lung function outcomes. We tested for effect modification by adding an interaction term to our main model and performed stratified analyses if the interaction term was significant $(p<0.10)$. Missing data for covariates were $<20 \%$, except for folic acid supplementation in early pregnancy $(22.6 \%)$. To reduce bias and imprecision, we imputed missing data of the covariates with multiple imputations $(\mathrm{m}=10)$ using the fully conditional specification method, and we reported the pooled effect estimates or odds ratios (OR) with their $95 \%$ confidence intervals (95\% CI). Statistical analyses were performed using SPSS version 25.0 for Windows (IBM Corp., Armonk, NY, USA).

\section{Results}

\subsection{Subject Characteristics}

The characteristics of mothers and children included in the analyses are shown in Table 1. The prevalence of current asthma was 5.7\% $(n=202)$, of inhalant allergic sensitization $32.7 \%(n=1007)$, and of physician-diagnosed inhalant allergy $12.2 \%(n=421)$. As compared with children in our analyses, those who were not included most importantly more often had mothers who had a lower education level, had less often a European ethnic background, and used less often folic acid supplementation (Supplementary Table S1).

\subsection{Maternal Fatty Acid Patterns and Respiratory and Allergy Outcomes}

In the basic model, we observed that a higher 'high n-6 PUFA' pattern was associated with a higher $\mathrm{FEV}_{1} / \mathrm{FVC}$ and $\mathrm{FEF}_{75}$. A higher 'MUFA and $\mathrm{SFA}^{\prime}$ pattern was associated with a lower $\mathrm{FEV}_{1} / \mathrm{FVC}$ and $\mathrm{FEF}_{75}$. A higher 'high n-3 PUFA' pattern was associated with a lower $\mathrm{FEV}_{1}, \mathrm{FEV}_{1} / \mathrm{FVC}$, and $\mathrm{FEF}_{75}$ (Table 2). After adjusting for confounders, only the associations of a 1 SD higher 'high n-6 PUFA' pattern with higher $\mathrm{FEV}_{1} / \mathrm{FVC}$ and $\mathrm{FEF}_{75}$ remained (Z-score difference $(95 \% \mathrm{CI}) 0.04(0,0.07)$ and $0.04(0.01,0.07)$, respectively) (Table 2$)$. These associations did not attenuate after further adjustment for gestational age at birth and birth weight (Z-score difference $(95 \% \mathrm{CI}) 0.04(0.01,0.07)$ and 0.04 $(0.01,0.08)$, respectively) or child's body mass index at the age of 10 years (Z-score difference $(95 \% \mathrm{CI})$ $0.04(0.01,0.07)$ and $0.04(0.01,0.07)$, respectively), and, therefore, further mediation analyses were not performed. We did not observe any associations of maternal fatty acids patterns with current asthma, inhalant allergic sensitization, or physician-diagnosed inhalant allergy (Table 2).

When studying maternal fatty acid patterns in quartiles with the lowest quartile as a reference, we mainly observed similar directions of the results as in the linear models, and there were no indications for non-linear associations between fatty acid patterns and respiratory or allergy outcomes (Supplementary Table S2). 
Table 1. Characteristics of mothers and children included in the analysis.

\begin{tabular}{|c|c|}
\hline & $n=4260$ \\
\hline \multicolumn{2}{|l|}{ Maternal Characteristics } \\
\hline Age, years & $30.8(4.8)$ \\
\hline Pre-pregnancy body mass index $\left(\mathrm{kg} / \mathrm{m}^{2}\right)^{1}$ & $22.6(18.0-34.6)$ \\
\hline Educational level, higher (\%) & $49.1(2093)$ \\
\hline Ethnic background, European (\%) & $64.8(2760)$ \\
\hline Parity, nullipara $(\%)$ & $58.3(2484)$ \\
\hline History of asthma or atopy, yes (\%) & $38.5(1640)$ \\
\hline Smoking during pregnancy, yes (\%) & $25.7(1096)$ \\
\hline Folic acid supplementation, yes (\%) & $76.9(3275)$ \\
\hline Total daily energy intake (kcal) & $2043(553)$ \\
\hline Gestational age at fatty acid measurement & $20.7(1.2)$ \\
\hline \multicolumn{2}{|l|}{ Standard deviation scores for fatty acid patterns } \\
\hline 'high n-6 PUFA' pattern & $-0.06(0.98)$ \\
\hline 'MUFA and SFA' pattern & $0.05(0.97)$ \\
\hline 'high n-3 PUFA' pattern & $0.08(0.99)$ \\
\hline \multicolumn{2}{|l|}{ Child Characteristics } \\
\hline Sex, female (\%) & $50.3(2142)$ \\
\hline Gestational age at birth (weeks) ${ }^{1}$ & $40.2(35.7-42.4)$ \\
\hline Birth weight (grams) & $3443(553)$ \\
\hline Ever breastfeeding, yes (\%) & $92.0(3920)$ \\
\hline Body mass index $\left(\mathrm{kg} / \mathrm{m}^{2}\right)$ & $17.6(2.8)$ \\
\hline $\mathrm{FEV}_{1}(\mathrm{z}$-score $)$ & $0.17(0.97)$ \\
\hline FVC (z-score) & $0.20(0.93)$ \\
\hline $\mathrm{FEV}_{1} / \mathrm{FVC}$ (z-score) & $-0.09(0.96)$ \\
\hline $\mathrm{FEF}_{75}(\mathrm{z}$-score $)$ & $0.04(0.92)$ \\
\hline Current asthma, yes (\%) & $5.7(202)$ \\
\hline Inhalant allergic sensitization, yes (\%) & $32.7(1007)$ \\
\hline Physician-diagnosed inhalant allergy, yes (\%) & $12.2(421)$ \\
\hline
\end{tabular}

Values are means (SD), ${ }^{1}$ medians (2.5-97.5th percentile), or valid percentages (absolute numbers), based on imputed data. Missing data on forced expiratory flow in $1 \mathrm{~s}\left(\mathrm{FEV}_{1}\right)(n=533)$, forced vital capacity (FVC) $(n=533), \mathrm{FEV}_{1} / \mathrm{FVC}$ ratio $(n=533)$, forced expiratory flow after exhaling $75 \%$ of $\mathrm{FVC}\left(\mathrm{FEF}_{75}\right)(n=533)$, current asthma $(n=734)$, inhalant allergic sensitization $(n=1182)$, physician-diagnosed inhalant allergy $(n=819)$ were not imputed. Polyunsaturated fatty acid (PUFA), monounsaturated fatty acid (MUFA), saturated fatty acid (SFA).

We did not find any associations of maternal fatty acid patterns with asthma severity divided into groups based on wheezing episodes (Supplementary Table S3).

We tested for interaction between the fatty acid patterns and maternal ethnic background, maternal asthma or atopy, and child's sex. We only observed a significant interaction of a 'high n-3 PUFA' pattern with maternal ethnic background on the $\operatorname{FEF}_{75}(p=0.01)$, and of a 'high n-6 PUFA' pattern with a maternal history of asthma or atopy on child's current asthma $(p=0.10)$ and physician-diagnosed inhalant allergy $(p=0.07)$, and of a 'high n-6 PUFA' pattern with child's sex on physician-diagnosed inhalant allergy $(p=0.05)$ (Supplementary Table S4). After stratification, none of the associations were statistically significant (Supplementary Table S4). When we tested for interaction between the fatty acid patterns and child's current asthma, inhalant allergic sensitization, and inhalant allergy, we observed a significant interaction between a 'high n-6 PUFA' pattern and child's current asthma on the association with $\mathrm{FEF}_{75}(p=0.05)$, between a 'high n-6 PUFA' pattern and inhalant allergic sensitization on the associations with $\mathrm{FEV}_{1} / \mathrm{FVC}(p=0.05)$ and $\mathrm{FEF}_{75}(p=0.08)$, and between a 'high n-6 PUFA' pattern and physician-diagnosed inhalant allergy on the association with FVC $(p=0.07)$ (Supplementary Table S5). Stratification by current asthma and inhalant allergic sensitization showed similar directions for the associations of a 'high n-6 PUFA' pattern with $\mathrm{FEV}_{1} / \mathrm{FVC}$ and $\mathrm{FEF}_{75}$ in children with and without asthma or inhalant allergic sensitization, and stratification by physician-diagnosed inhalant allergy showed no consistent associations of a 'high n-6 PUFA' pattern with FVC (Supplementary Table S5). 
Table 2. Associations of maternal fatty acid patterns with respiratory and allergy outcomes in children at the age of 10 years.

\begin{tabular}{|c|c|c|c|c|c|c|c|}
\hline Fatty Acid Pattern (per SD) & $\begin{array}{c}\text { FEV }_{1} \text { Z-Score } \\
\text { Change }(95 \% \text { CI) } \\
n=3727\end{array}$ & $\begin{array}{c}\text { FVC Z-Score } \\
\text { Change }(95 \% \text { CI }) \\
n=3727\end{array}$ & $\begin{array}{c}\text { FEV }_{1} / \text { FVC Z-Score } \\
\text { Change }(95 \% \text { CI) } \\
n=3727\end{array}$ & $\begin{array}{c}\mathrm{FEF}_{75} \mathrm{Z} \text {-Score } \\
\text { Change }(95 \% \mathrm{CI}) \\
n=3727\end{array}$ & $\begin{array}{c}\text { Current Asthma } \\
\text { OR }(95 \% \text { CI }) \\
n=3526\end{array}$ & $\begin{array}{l}\text { Inhalant Allergic } \\
\text { Sensitization OR } \\
(95 \% \text { CI) } n=3078\end{array}$ & $\begin{array}{c}\text { Inhalant Allergy } \\
\text { OR }(95 \% \text { CI }) \\
n=3441\end{array}$ \\
\hline \multicolumn{8}{|l|}{ Model 1: Basic model } \\
\hline 'high n-6 PUFA' pattern & $0.01(-0.03,0.04)$ & $-0.02(-0.05,0.01)$ & $0.04(0.01,0.07) *$ & $0.05(0.02,0.08)^{* *}$ & $1.10(0.95,1.26)$ & $0.95(0.88,1.02)$ & $0.98(0.88,1.08)$ \\
\hline 'MUFA and SFA' pattern & $-0.01(-0.04,0.03)$ & $0.01(-0.02,0.04)$ & $-0.04(-0.07,-0.01) *$ & $-0.04(-0.07,-0.01)^{* *}$ & $1.06(0.91,1.23)$ & $0.98(0.91,1.06)$ & $1.02(0.91,1.13)$ \\
\hline 'high n-3 PUFA' pattern & $-0.04(-0.07,-0)^{*}$ & $-0.02(-0.05,0.01)$ & $-0.04(-0.07,-0.01) *$ & $-0.04(-0.07,-0.02) * *$ & $0.94(0.81,1.09)$ & $1.03(0.95,1.11)$ & $0.98(0.89,1.09)$ \\
\hline \multicolumn{8}{|l|}{ Model 2: Confounder model } \\
\hline ‘high n-6 PUFA' pattern & $0.01(-0.03,0.04)$ & $-0.02(-0.05,0.02)$ & $0.04(0,0.07) *$ & $0.04(0.01,0.07) * *$ & $1.06(0.91,1.23)$ & $0.95(0.88,1.03)$ & $0.98(0.88,1.09)$ \\
\hline 'MUFA and SFA' pattern & $0.01(-0.03,0.04)$ & $0.01(-0.01,0.05)$ & $-0.02(-0.05,0.02)$ & $-0.01(-0.04,0.02)$ & $1.12(0.96,1.30)$ & $1.02(0.94,1.10)$ & $1.07(0.96,1.20)$ \\
\hline ‘high n-3 PUFA' pattern & $-0.02(-0.05,0.02)$ & $-0.01(-0.04,0.02)$ & $-0.01(-0.05,0.02)$ & $-0.01(-0.04,0.03)$ & $1.02(0.87,1.18)$ & $1.08(0.99,1.17)$ & $1.05(0.94,1.17)$ \\
\hline
\end{tabular}

Values are Z-score changes or odds ratios (OR) with 95\% confidence interval (95\% CI), derived from linear or logistic regression models per SD increase in the fatty acid patterns.

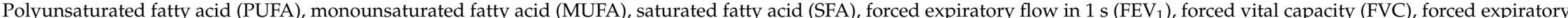
flow after exhaling $75 \%$ of FVC ( $\mathrm{FEF}_{75}$ ). Fatty acids are classified into three patterns, derived from the principal component analysis: 'High n6 PUFA' pattern, 'MUFA and SFA' pattern, and 'High n-3 PUFA' pattern. Model 1 (basic model) was adjusted for gestational age at fatty acid measurement and child's sex. Model 2 (confounder model) was additionally adjusted for maternal age, pre-pregnancy body mass index, educational level, ethnic background, parity, smoking during pregnancy, folic acid supplementation, total daily energy intake, and child's breastfeeding. ${ }^{*} p$-value $<0.05$ and ${ }^{* *} p$-value $<0.01$. 


\section{Discussion}

In this population-based prospective cohort study, we observed that a fatty acid pattern characterized by high concentrations of maternal n-6 PUFAs in pregnancy was associated with a higher $\mathrm{FEV}_{1} / \mathrm{FVC}$ and $\mathrm{FEF}_{75}$ in the children aged 10 years. Patterns characterized by high concentrations of most of the MUFAs or high concentrations of n-3 PUFAs were not consistently associated with a child's lung function. We did not observe any associations of maternal fatty acid patterns with asthma or allergy outcomes in the children at school-age.

\subsection{Comparison with Previous Studies}

Only a single previous study examined the associations of maternal PUFA concentrations during pregnancy with a child's lung function as measured by spirometry, showing no association of maternal PUFA concentrations during pregnancy with $\mathrm{FEV}_{1}$ in 6-year-old children, but other lung function outcomes were not taken into consideration [8]. We previously observed in younger children that higher maternal $\gamma$-linolenic acid (18:3n-6) and dihomo- $\gamma$-linolenic acid (20:3n-6) concentrations, both n-6 PUFAs, in pregnancy were associated with a lower airway resistance in the children at the age of 6 years, as measured by interrupter technique (Rint) [7]. We now additionally showed that a higher 'high n-6 PUFA' pattern during pregnancy, which includes both $\gamma$-linolenic acid and dihomo- $\gamma$-linolenic acid with high positive loadings, was associated with a better lung function at the age of 10 years, as reflected by $\mathrm{FEV}_{1} / \mathrm{FVC}$ and $\mathrm{FEF}_{75}$, which are more robust markers of airway obstruction.

Like most previous cohort studies on maternal fatty acid concentrations and an individual participant meta-analysis on the maternal intake of fish, being the main source of n-3 PUFAs, we did not find associations of maternal n-3 or n-6 PUFA's during pregnancy with asthma, inhalant allergic sensitization, or physician-diagnosed inhalant allergy [8-10,22]. However, we previously observed in our cohort that a higher maternal total n-6 PUFA concentration was associated with a lower risk of asthma, whereas we did not find an association of a 'high n-6 PUFA' pattern with asthma in the current study [7]. Differences might be due to assessment of PUFAs in groups versus patterns, or the age at which asthma was assessed, at a younger age, as it is difficult to distinguish asthma from a viral-induced wheeze. A recent literature-based meta-analysis of randomized controlled trials mainly included studies with a follow-up until infancy and did not find a beneficial effect of $n-3$ PUFA supplementation in pregnancy on wheezing or asthma in the children [23]. Randomized controlled trials with a longer follow-up until school-age or young adulthood suggested that prenatal n-3 PUFA supplementation reduced the risk of asthma, although no consistent effect on lung function or allergy development was observed [6,24-26]. The beneficial effect of high-dose n-3 PUFA supplementation on asthma was the strongest in children of mothers with the lowest n-3 PUFA concentrations. Fish intake in The Netherlands and in the Generation R cohort is relatively low compared to other European countries [22,27]. It might be that the range of n-3 PUFA concentrations was too narrow in our cohort to detect a beneficial effect of higher maternal n-3 PUFA concentrations on a child's asthma. Another explanation for the inconsistent results might be that the intervention trials were mainly performed in late pregnancy, whereas we assessed maternal n-3 PUFA concentrations in mid-pregnancy.

To our best knowledge, no previous studies examined the associations of maternal SFA and MUFA concentrations with a child's respiratory or allergy outcomes at school-age. Although one study in Japanese mothers did not find an association of SFA or MUFA intake estimated from a questionnaire in pregnancy with wheezing at preschool age [28]. More studies on the effect of patterns of maternal PUFA, SFA, and MUFA concentrations at different time-points in pregnancy with a child's respiratory and allergy outcomes at older ages are needed.

\subsection{Interpretation of the Results}

The observation of an association between high n-6 PUFA and better lung function at 10 years might be related to the immunological effects of a 'high n-6 PUFA' pattern. Arachidonic acid (20:4n-6), 
an important component in this pattern, can be converted into metabolites, including prostaglandin $\mathrm{E} 2\left(\mathrm{PGE}_{2}\right)$ [2]. Although $\mathrm{PGE}_{2}$ might enhance allergic inflammation, it seems to have an opposing and anti-inflammatory effect in the airway system [3]. Airway epithelium and smooth muscle are the main producers of $\mathrm{PGE}_{2}$, and $\mathrm{PGE}_{2}$ reduces bronchoconstriction, relaxes airway smooth muscle, and inhibits the recruitment of inflammatory cells and mast cell mediators [29,30]. These effects might contribute to a higher $\mathrm{FEV}_{1} / \mathrm{FVC}$ ratio and $\mathrm{FEF}_{75}$. The fatty acid metabolism and, consequently, the production of metabolites, including $\mathrm{PGE}_{2}$, might depend on genetic factors and differ between mothers or children with and without a history of atopic diseases [31]. However, although some $p$-values for interaction were significant, we did not observe differences in results among groups after stratification. We therefore considered that interaction between maternal ethnic background, maternal asthma or atopy, child's sex, and child's asthma or allergy and fatty acid patterns on the associations with lung function was minimally present. N-3 PUFAs might inhibit fetal T-helper 2 (Th2) responses through effects on the expression of genes and the production of pro-inflammatory eicosanoids, thereby lowering the risk of asthma and allergy [32]. During pregnancy, docosahexaenoic acid (22:6n-3) concentrations, one of the main n-3 PUFAs, increase until 18 weeks of gestation through mobilization from maternal stores, but concentrations decline to a deficiency in the third trimester [33]. This might explain the different observations between the randomized controlled trials in the third trimester and our study in mid-pregnancy.

The 'MUFA and SFA' pattern was characterized by high positive loadings of most of the MUFAs and of the SFAs - myristic acid (14:0) and palmitic acid (16:0) — but high negative loadings of the SFAs—-margaric acid (17:0) and stearic acid (18:0). Different SFAs and MUFAs, such as palmitic acid and oleic acid, might have opposite inflammatory effects, which might explain a lack of association of this pattern with respiratory or allergy outcomes [34]. Furthermore, although PUFAs are transferred over the placenta, the fetus might synthesize MUFAs and SFAs de novo from glucose [35]. Maternal MUFA and SFA concentrations might, therefore, not fully reflect the fetal status of these fatty acids.

Despite the small effect estimates and absence of an association with clinical disease, our findings might be of importance from a developmental and population perspective. Fatty acid concentrations might partly depend on genetic and metabolic influences, although maternal diet might also play a role as $7.5 \%$ of the variation in the fatty acid patterns in our population was explained by differences in food intake [12]. Our results, therefore, suggest that future intervention studies should explore, in addition to the intake of maternal n-3 PUFAs, the intake of n-6 PUFAs and the interrelation between the different PUFA's, as well as the role of genetic and metabolic influences in relation to respiratory and allergy outcomes in the children later in life.

\subsection{Strengths and Limitations}

This study was embedded in a large prospective population-based cohort study. We had detailed information available on maternal fatty acid concentrations during pregnancy and were able to examine fatty acids in patterns, which take the interrelation between individual fatty acids into account and avoid the chance of false-positive findings [12]. However, some limitations need to be mentioned. First, non-response analyses suggested a selection to a more healthy population, which would have led to biased estimates if the associations of interest were different between participants and non-participants. Second, although we measured a large number of individual PUFAs, they were only measured once in mid-pregnancy and, therefore, mainly reflect the dietary intake and metabolism of fatty acids in the preceding weeks but not in other periods of pregnancy [36]. Third, although we used validated and widely used questionnaires to assess asthma and physician-diagnosed inhalant allergy, information bias might have occurred, which might lead to under- or overestimations of the observed associations. Severe asthma in the general population is relatively uncommon. We therefore used an epidemiological approach based on the number of wheezing episodes, limiting the generalizability of the results. Lastly, although we adjusted for several sociodemographic and lifestyle-related confounders, we could not exclude residual confounding. 


\section{Conclusions}

A maternal fatty acid pattern characterized by high levels of n-6 PUFAs in mid-pregnancy was associated with a better lung function, especially a higher $\mathrm{FEV}_{1} / \mathrm{FVC}$ ratio and $\mathrm{FEF}_{75}$, in school-aged children. We did not find consistent associations of fatty acid patterns with asthma or allergy outcomes. Future studies on the causality and clinical implications of the relation of a pattern of high n- 6 PUFA concentrations in pregnancy with a better lung function in school-aged children are needed.

Supplementary Materials: The following are available online at http://www.mdpi.com/2072-6643/12/10/3057/s1, Figure S1: Flow chart of participants included for analysis, Figure S2: Factor loadings of maternal individual fatty acids in fatty acid patterns, Table S1: Comparison of baseline characteristics between participants and non-participants in the analysis, Table S2: Associations of maternal fatty acid patterns in quartiles with respiratory and allergy outcomes in children at the age of 10 years, Table S3: Associations of maternal fatty acid patterns with asthma severity divided in groups based on wheezing episodes, Table S4: Associations of maternal fatty acid patterns with respiratory outcomes in children at the age of 10 years, stratified by maternal ethnic background, maternal history of asthma or atopy, and child's sex, Table S5: Associations of maternal fatty acid patterns with respiratory outcomes in children at the age of 10 years, stratified by current asthma, inhalant allergic sensitization, and inhalant allergy.

Author Contributions: Conceptualization, S.M.M.-B., T.V., V.W.V.J., and L.D.; Data curation, S.M.M.-B., T.V., V.W.V.J., and L.D.; Formal analysis, S.M.M.-B, T.V., M.D., and L.D.; Funding acquisition, V.W.V.J. and L.D.; Methodology, S.M.M.-B., T.V., V.W.V.J., and L.D.; Project administration, S.M.M.-B. and L.D.; Supervision, V.W.V.J. and L.D.; Writing-original draft, S.M.M.-B., M.D., and L.D.; Writing-Review and editing, S.M.M.-B., T.V., I.K.M.R., J.C.D.J., V.W.V.J., and L.D. All authors have read and agreed to the published version of the manuscript.

Funding: The Generation R Study is made possible by financial support from the Erasmus Medical Center, Rotterdam, the Erasmus University Rotterdam, and The Netherlands Organization for Health Research and Development. Marsela Dervishaj received an EAACI Research Fellowship for this project. This project received funding from the European Union's Horizon 2020 research and innovation program (LIFECYCLE, grant agreement No 733206, 2016; EUCAN-Connect grant agreement No 824989; ATHLETE, grant agreement No 874583). Liesbeth Duijts received funding from the European Union's Horizon 2020 co-funded program ERA-Net on Biomarkers for Nutrition and Health (ERA HDHL) (ALPHABET project (no 696295; 2017), ZonMW The Netherlands (no 529051014; 2017)). Vincent Jaddoe received support from the European Research Council Consolidator Grant (ERC-2014-CoG-648916). The study sponsors had no role in the study design, data analysis, interpretation of data, or writing of this report.

Acknowledgments: The Generation R Study is conducted by the Erasmus Medical Center in close collaboration with the School of Law and the Faculty of Social Sciences at the Erasmus University, Rotterdam, the Municipal Health Service, Rotterdam area, and the Stichting Trombosedienst and Artsenlaboratorium Rijnmond (Star-MDC), Rotterdam. We gratefully acknowledge the contribution of children and their parents, general practitioners, hospitals, midwives, and pharmacies in Rotterdam.

Conflicts of Interest: The authors declare no conflict of interest.

\section{References}

1. Beckhaus, A.A.; Garcia-Marcos, L.; Forno, E.; Pacheco-Gonzalez, R.M.; Celedon, J.C.; Castro-Rodriguez, J.A. Maternal nutrition during pregnancy and risk of asthma, wheeze, and atopic diseases during childhood: A systematic review and meta-analysis. Allergy 2015, 70, 1588-1604. [CrossRef] [PubMed]

2. Black, P.N.; Sharpe, S. Dietary fat and asthma: Is there a connection? Eur. Respir. J. 1997, 10, 6-12. [CrossRef] [PubMed]

3. Miles, E.A.; Calder, P.C. Can early omega-3 fatty acid exposure reduce risk of childhood allergic disease? Nutrients 2017, 9, 784. [CrossRef] [PubMed]

4. Wendell, S.G.; Baffi, C.; Holguin, F. Fatty acids, inflammation, and asthma. J. Allergy Clin. Immunol. 2014, 133, 1255-1264. [CrossRef] [PubMed]

5. Yang, X.; Haghiac, M.; Glazebrook, P.; Minium, J.; Catalano, P.M.; Hauguel-de Mouzon, S. Saturated fatty acids enhance tlr4 immune pathways in human trophoblasts. Hum. Reprod. 2015, 30, 2152-2159. [CrossRef]

6. Bisgaard, H.; Stokholm, J.; Chawes, B.L.; Vissing, N.H.; Bjarnadottir, E.; Schoos, A.M.; Wolsk, H.M.; Pedersen, T.M.; Vinding, R.K.; Thorsteinsdottir, S.; et al. Fish oil-derived fatty acids in pregnancy and wheeze and asthma in offspring. N. Engl. J. Med. 2016, 375, 2530-2539. [CrossRef] 
7. Rucci, E.; den Dekker, H.T.; de Jongste, J.C.; Steenweg-de-Graaff, J.; Gaillard, R.; Pasmans, S.G.; Hofman, A.; Tiemeier, H.; Jaddoe, V.W.; Duijts, L. Maternal fatty acid levels during pregnancy, childhood lung function and atopic diseases. The generation r study. Clin. Exp. Allergy 2016, 46, 461-471. [CrossRef]

8. Pike, K.C.; Calder, P.C.; Inskip, H.M.; Robinson, S.M.; Roberts, G.C.; Cooper, C.; Godfrey, K.M.; Lucas, J.S. Maternal plasma phosphatidylcholine fatty acids and atopy and wheeze in the offspring at age of 6 years. Clin. Dev. Immunol. 2012, 2012, 474613. [CrossRef]

9. Notenboom, M.L.; Mommers, M.; Jansen, E.H.; Penders, J.; Thijs, C. Maternal fatty acid status in pregnancy and childhood atopic manifestations: Koala birth cohort study. Clin. Exp. Allergy 2011, 41, 407-416. [CrossRef]

10. Standl, M.; Demmelmair, H.; Koletzko, B.; Heinrich, J. Cord blood lc-pufa composition and allergic diseases during the first 10 yr. Results from the lisaplus study. Pediatr. Allergy Immunol. 2014, 25, 344-350. [CrossRef]

11. Gibson, R.A.; Muhlhausler, B.; Makrides, M. Conversion of linoleic acid and alpha-linolenic acid to long-chain polyunsaturated fatty acids (lcpufas), with a focus on pregnancy, lactation and the first 2 years of life. Matern. Child Nutr. 2011, 7, 17-26. [CrossRef] [PubMed]

12. Voortman, T.; Tielemans, M.J.; Stroobant, W.; Schoufour, J.D.; Kiefte-de Jong, J.C.; Steenweg-de Graaff, J.; van den Hooven, E.H.; Tiemeier, H.; Jaddoe, V.W.V.; Franco, O.H. Plasma fatty acid patterns during pregnancy and child's growth, body composition, and cardiometabolic health: The generation r study. Clin. Nutr. 2018, 37, 984-992. [CrossRef] [PubMed]

13. Kooijman, M.N.; Kruithof, C.J.; van Duijn, C.M.; Duijts, L.; Franco, O.H.; van Ijzendoorn, M.H.; de Jongste, J.C.; Klaver, C.C.; van der Lugt, A.; Mackenbach, J.P.; et al. The generation r study: Design and cohort update 2017. Eur. J. Epidemiol. 2016, 31, 1243-1264. [CrossRef] [PubMed]

14. Kruithof, C.J.; Kooijman, M.N.; van Duijn, C.M.; Franco, O.H.; de Jongste, J.C.; Klaver, C.C.; Mackenbach, J.P.; Moll, H.A.; Raat, H.; Rings, E.H.; et al. The generation r study: Biobank update 2015. Eur. J. Epidemiol. 2014, 29, 911-927. [CrossRef] [PubMed]

15. Steenweg-de Graaff, J.C.; Tiemeier, H.; Basten, M.G.; Rijlaarsdam, J.; Demmelmair, H.; Koletzko, B.; Hofman, A.; Jaddoe, V.W.; Verhulst, F.C.; Roza, S.J. Maternal lc-pufa status during pregnancy and child problem behavior: The generation r study. Pediatr. Res. 2015, 77, 489-497. [CrossRef] [PubMed]

16. Miller, M.R.; Hankinson, J.; Brusasco, V.; Burgos, F.; Casaburi, R.; Coates, A.; Crapo, R.; Enright, P.; van der Grinten, C.P.; Gustafsson, P.; et al. Standardisation of spirometry. Eur. Respir. J. 2005, 26, 319-338. [CrossRef] [PubMed]

17. Quanjer, P.H.; Stanojevic, S.; Cole, T.J.; Baur, X.; Hall, G.L.; Culver, B.H.; Enright, P.L.; Hankinson, J.L.; Ip, M.S.; Zheng, J.; et al. Multi-ethnic reference values for spirometry for the 3-95-yr age range: The global lung function 2012 equations. Eur. Respir. J. 2012, 40, 1324-1343. [CrossRef]

18. Asher, M.I.; Keil, U.; Anderson, H.R.; Beasley, R.; Crane, J.; Martinez, F.; Mitchell, E.A.; Pearce, N.; Sibbald, B.; Stewart, A.W.; et al. International study of asthma and allergies in childhood (isaac): Rationale and methods. Eur. Respir. J. 1995, 8, 483-491. [CrossRef]

19. Van der Valk, J.P.M.; Gerth van Wijk, R.; Hoorn, E.; Groenendijk, L.; Groenendijk, I.M.; de Jong, N.W. Measurement and interpretation of skin prick test results. Clin. Transl. Allergy 2015, 6, 8. [CrossRef]

20. Fredriks, A.M.; van Buuren, S.; Wit, J.M.; Verloove-Vanhorick, S.P. Body index measurements in 1996-7 compared with 1980. Arch. Dis. Child. 2000, 82, 107-112. [CrossRef]

21. Nurmatov, U.; Nwaru, B.I.; Devereux, G.; Sheikh, A. Confounding and effect modification in studies of diet and childhood asthma and allergies. Allergy 2012, 67, 1041-1059. [CrossRef] [PubMed]

22. Stratakis, N.; Roumeliotaki, T.; Oken, E.; Ballester, F.; Barros, H.; Basterrechea, M.; Cordier, S.; de Groot, R.; den Dekker, H.T.; Duijts, L.; et al. Fish and seafood consumption during pregnancy and the risk of asthma and allergic rhinitis in childhood: A pooled analysis of 18 european and us birth cohorts. Int. J. Epidemiol. 2017, 46, 1465-1477. [CrossRef] [PubMed]

23. Vahdaninia, M.; Mackenzie, H.; Dean, T.; Helps, S. $\Omega-3$ lcpufa supplementation during pregnancy and risk of allergic outcomes or sensitization in offspring: A systematic review and meta-analysis. Ann. Allergy Asthma Immunol. 2019, 122, 302-313. [CrossRef] [PubMed]

24. Hansen, S.; Strøm, M.; Maslova, E.; Dahl, R.; Hoffmann, H.J.; Rytter, D.; Bech, B.H.; Henriksen, T.B.; Granström, C.; Halldorsson, T.I.; et al. Fish oil supplementation during pregnancy and allergic respiratory disease in the adult offspring. J. Allergy Clin. Immunol. 2017, 139, 104-111. [CrossRef] [PubMed] 
25. Best, K.P.; Sullivan, T.; Palmer, D.; Gold, M.; Kennedy, D.J.; Martin, J.; Makrides, M. Prenatal fish oil supplementation and allergy: 6-year follow-up of a randomized controlled trial. Pediatrics 2016, 137. [CrossRef]

26. Olsen, S.F.; Østerdal, M.L.; Salvig, J.D.; Mortensen, L.M.; Rytter, D.; Secher, N.J.; Henriksen, T.B. Fish oil intake compared with olive oil intake in late pregnancy and asthma in the offspring: $16 \mathrm{y}$ of registry-based follow-up from a randomized controlled trial. Am. J. Clin. Nutr. 2008, 88, 167-175. [CrossRef]

27. Welch, A.A.; Lund, E.; Amiano, P.; Dorronsoro, M.; Brustad, M.; Kumle, M.; Rodriguez, M.; Lasheras, C.; Janzon, L.; Jansson, J.; et al. Variability of fish consumption within the 10 european countries participating in the european investigation into cancer and nutrition (epic) study. Public Health Nutr. 2002, 5, 1273-1285. [CrossRef]

28. Miyake, Y.; Sasaki, S.; Tanaka, K.; Ohfuji, S.; Hirota, Y. Maternal fat consumption during pregnancy and risk of wheeze and eczema in japanese infants aged 16-24 months: The osaka maternal and child health study. Thorax 2009, 64, 815-821. [CrossRef]

29. Sastre, B.; del Pozo, V. Role of pge2 in asthma and nonasthmatic eosinophilic bronchitis. Mediat. Inflamm. 2012, 2012, 645383. [CrossRef]

30. Pavord, I.D.; Tattersfield, A.E. Bronchoprotective role for endogenous prostaglandin e2. Lancet 1995, 345, 436-438. [CrossRef]

31. Duchén, K.; Björkstén, B. Polyunsaturated n-3 fatty acids and the development of atopic disease. Lipids 2001, 36, 1033-1042. [CrossRef] [PubMed]

32. Calder, P.C.; Krauss-Etschmann, S.; de Jong, E.C.; Dupont, C.; Frick, J.S.; Frokiaer, H.; Heinrich, J.; Garn, H.; Koletzko, S.; Lack, G.; et al. Early nutrition and immunity—Progress and perspectives. Br. J. Nutr. 2006, 96, 774-790. [PubMed]

33. Al, M.D.; van Houwelingen, A.C.; Kester, A.D.; Hasaart, T.H.; de Jong, A.E.; Hornstra, G. Maternal essential fatty acid patterns during normal pregnancy and their relationship to the neonatal essential fatty acid status. Br. J. Nutr. 1995, 74, 55-68. [CrossRef] [PubMed]

34. Jeffery, N.M.; Cortina, M.; Newsholme, E.A.; Calder, P.C. Effects of variations in the proportions of saturated, monounsaturated and polyunsaturated fatty acids in the rat diet on spleen lymphocyte functions. Br. J. Nutr. 1997, 77, 805-823. [CrossRef]

35. Lewis, R.M.; Childs, C.E.; Calder, P.C. New perspectives on placental fatty acid transfer. Prostaglandins Leukot. Essent. Fat. Acids 2018, 138, 24-29. [CrossRef]

36. Hodson, L.; Skeaff, C.M.; Fielding, B.A. Fatty acid composition of adipose tissue and blood in humans and its use as a biomarker of dietary intake. Prog. Lipid Res. 2008, 47, 348-380. [CrossRef] 